\title{
Simple Efficient Contracts in Complex Environments
}

\author{
Robert Evans
}

March 2006

CWPE 0627

Not to be quoted without permission 


\title{
Simple Efficient Contracts in Complex Environments
}

\author{
Robert Evans \\ St. John's College, Cambridge, UK. \\ robert.evans@econ.cam.ac.uk \\ First version: March 2002 \\ This version: September 2005
}

\begin{abstract}
The paper studies a general model of hold-up in a setting encompassing the models of Segal (1999) and Che and Hausch (1999) among others. It is shown that if renegotiation is modelled as an infinite-horizon non-cooperative bargaining game then, with a simple initial contract, an efficient equilibrium will generally exist. The contract gives authority to one party to set the terms of trade and gives the other party a non-expiring option to trade at these terms. The difference from standard results arises because the existing contract ensures that the renegotiation game has multiple equilibria; the multiplicity of continuation equilibria can be used to enforce efficient investment.
\end{abstract}

JEL: D23

Keywords: Incomplete Contracts, Hold-up problem, Option Contracts

This is a substantially-revised version of a paper entitled "Efficient Contracts in Complex Environments". Thanks are due for helpful discussions and comments to Ben Polak, and to seminar audiences at Toulouse, Edinburgh, Birmingham and UCL. 


\section{Introduction}

The classical hold-up problem is that if two individuals who must make relationshipspecific investments might subsequently renegotiate the division of the surplus which results, they will under-invest because they will not both be able to realize the full marginal benefit of their investment. The literature on the hold-up problem has been very fruitful in providing explanations for a variety of economic institutions and contracting practices such as, for example, vertical integration, property rights and financial structure of firms (Klein, Crawford and Alchian (1978), Williamson (1979), Grossman and Hart (1986), Aghion and Bolton (1992)). Some papers have argued that the hold-up problem can be solved by appropriate contractual design. Most notably, Aghion, Dewatripont and Rey (1994) (see also Chung (1991)) showed that in some situations the renegotiation game can be altered by contractual devices in such a way as to induce efficient investment, while Nöldeke and Schmidt (1995) showed that option contracts may in certain circumstances achieve efficiency. These papers, however, refer to situations in which, firstly, it is clear ex ante which good should be traded ex post (i.e., after the uncertainty is resolved) and, secondly, bilateral direct externalities do not obtain (for example, in a buyer-seller model, it is not the case that the buyer's investment affects the seller's production cost and the seller's investment affects the value of the good to the buyer, clearly a strong assumption in many applications). Che and Hausch (1999) showed that if bilateral direct externalities are incorporated in the standard model, and if a commitment not to renegotiate the contract is impossible, then it may be that contracts are able to achieve nothing: the optimal complete contract is the null contract and the inefficiency caused by the hold-up problem is severe. Furthermore, Segal (1999) and Hart and Moore (1999) showed that a similar conclusion obtains if the environment is complex in the sense that the nature of the good which it will be efficient ex post to trade is not known and there are many goods which might turn out to be the efficient one.

The purpose of this paper is to argue that simple contracts similar in some ways to those considered by Aghion, Dewatripont and Rey (1994) (henceforth ADR) and by 
Nöldeke and Schmidt (1995) can in fact lead to efficiency even when the environment is complex and when there are bilateral direct externalities. We consider a buyer-seller model with two-sided investments encompassing, among others, settings of the types studied by Che and Hausch (1999), Segal (1999) and Hart and Moore (1999). We adopt the view that there is an exogenously given non-cooperative renegotiation game, which we take to be an infinite-horizon game: that is, the seller can delay production, and/or the buyer can delay acceptance of the good, for an indefinite period while contract renegotiation is going on. The result is that there are simple contracts with the property that, for a large class of plausible non-cooperative renegotiation games, there exists an efficient equilibrium. Two important advantages of the contracts which are used to achieve efficiency are, firstly, that they are very simple and, secondly, that they do not assume that future contingencies are describable ex ante. They give one party the authority to set ex post the nature and terms of trade and they give the other party a non-expiring option whether to trade or not. They may also require one party to post a bond as a guarantee of good behavior. Although, as noted above, there are similarities between these contracts and those considered by ADR and NöldekeSchmidt, there are also significant differences. Whereas in the latter two papers the default option is set ex ante in the original contract, here it is set ex post by one of the parties (the one with authority); furthermore, the default trade cannot be enforced by each party since the one without authority always has the option not to trade. Similarly, whereas the Nöldeke-Schmidt model has a finite horizon, so that the option necessarily has to be exercised by a specific date or not at all, the options considered here never expire.

More importantly, the logic of the equilibrium considered here is very different from that found in previous papers. Suppose that the party with authority is the buyer. After the investments have been made and the uncertainty has been resolved the buyer's equilibrium strategy will be to specify an efficient trade. Subsequently, since trading according to the terms of the existing contract is efficient, there will be an equilibrium in which there is no renegotiation of the contract and the parties do indeed trade efficiently on these terms. On the other hand, there will also exist another 
equilibrium in which, essentially, the seller declines to exercise her option and bargains over a new contract. Since there are multiple equilibria in the continuation game, it is possible to condition the equilibrium played on the investments which were made in the first stage, giving both parties the incentive to invest efficiently (depending on the parameters, it may also be necessary to use a financial hostage to influence the shares of surplus which the two parties get in renegotiation). Equally, if the buyer abuses his authority by specifying either an inefficient trade or the wrong terms of trade, he can be punished by selection of an appropriate continuation equilibrium. The argument relies on the fact that there are multiple equilibria in the renegotiation game. This explains the difference between the results of this paper and those of earlier papers: typically earlier papers assume (often without an explicit non-cooperative analysis) that the renegotiation game has a unique outcome. Non-cooperative bargaining games (the Rubinstein game, say) do often have a unique equilibrium. However, we are dealing here with a game in which there already exists a contract (perhaps a contract which gives, or may give, an efficient outcome, depending on the moves which the parties make), but renegotiation can take place according to some given protocol. This is different from a game in which there is no contract and in which the players, using the same protocol, have to negotiate an agreement before any surplus can be realized. For any of the standard bargaining protocols, there will necessarily be multiple equilibria in the renegotiation game starting with a contract of the type considered here in force.

The argument relies on an assumption - implicit in the definition of subgameperfect equilibrium - that the parties' behavior (in particular, the resulting distribution of surplus) can be history-dependent. The view taken here is that, once two parties have reached an agreement, partly formal (i.e., legally enforceable) and partly informal, the behavior of each will depend on whether the other has violated the agreement or not. The alternative view would be that in the absence of a forcing contract the distribution of surplus should always be independent of history, but this view, as argued below, is not supported by non-cooperative analysis of plausible extensive-form games. Nor does it seem to be compatible with empirical or exper- 
imental evidence that an agent's behavior is always invariant to the past behavior of the agent with whom he or she is interacting. For example, Kahneman, Knetsch and Thaler (1986), Bewley (1997) and Borges and Knetsch (1997) provide evidence that the bargains which customers, employees and experimental subjects are willing to make depend on the size and nature of sunk costs which have been previously incurred.

A number of conclusions follow from the analysis. As several of the papers mentioned above have found, contracts which are very incomplete (e.g., authority contracts) may in fact be optimal, particularly when renegotiation is allowed. Our results lend support to this conclusion. Bolton and Rajan (2001) have shown, in an asymmetric information framework with repeated interaction, that employment contracts may be optimal. The contracts in the current paper look very like employment contracts since one party gives instructions and the other has the legal right, in effect, to strike and negotiate for better terms. We find that such contracts are efficient even in a symmetric information framework which is essentially one-shot (in the sense that it is a one-off project - only one good is to be produced). We also find (in Section 4) that if it is not possible for the parties to deposit a financial hostage then it is optimal to give authority to that party which, other things being equal, has relatively high investment cost or low bargaining power. If the 'employer' has high bargaining power then the threat of a 'strike' by the 'employee' is too low to give the former the incentive to invest enough in the relationship. If financial hostages are feasible, then either party could be given authority.

Secondly, an explicitly non-cooperative analysis may yield different conclusions from those of standard contract theory. The latter generally assumes either that, as discussed above, there is a black-box renegotiation process or else that the contract can effectively design an entire extensive form for the parties to play. Here we assume, by contrast, that the contract can only overlay an existing non-cooperative game which the parties play, an approach which Aghion, Dewatripont and Rey (2002) have called 'partial contracting'. The literature on relational contracting (see Macleod and Malcomson (1989) and Levin (2003)) has a similar outlook. A related point, 
which has been stressed by Watson (2001) is that if the parties can take costly and irreversible actions as part of the mechanism (as opposed to simply send messages as in classical contract theory ${ }^{1}$ ) then the implementable outcomes will be very different.

Thirdly, we conclude that lack of verifiability is not necessarily an obstacle to efficient contracting even in those environments in which it has been supposed to be fatal. Undoubtedly contracting is inefficient in many circumstances but it may be that the explanation for this is to be found either in asymmetry of information or in a lack of ex post verifiability ${ }^{2}$ - here we assume, as does most of the hold-up literature, that actions are contractible after the uncertainty is resolved.

A recent paper which sets out an argument related to the one made here is Che and Sakovics (2003). They assume that the parties are able to delay their investment indefinitely and that bargaining over the surplus goes on while, possibly, investment gradually takes place. Their result is that even if there is no contract there will be an asymptotically efficient equilibrium, as the discount factor goes to one. The difference from the current paper is that we assume, in common with most of the rest of the holdup literature, that the investment of the two parties has to be made, simultaneously, at the outset of the game. It may be, for example, that if the investment is delayed then other firms will come in and take the market, so that substantial sums have to be committed at the outset if the project is to have a positive net present value.

Another related paper is Carmichael and MacLeod (2003). They analyze a holdup model in which, after investing, the two players play a modified version of the one-shot Nash demand game. This game has an efficient equilibrium: neither party wants to reduce his investment below the efficient level because his proportional share of the ex post surplus would fall. The bargaining game, however, is special. Moreover, if the two parties do not reach agreement they will presumably re-open negotiations rather than walk away, i.e., the equilibrium is not renegotiation-proof. The difference from the current paper is that we show here that if delay in production is possible,

\footnotetext{
${ }^{1}$ See Maskin and Moore (1999) for the standard approach to mechanism design with renegotiation. In this approach, the mechanism delivers an outcome, as a function of messages which are intrinsically costless, which may be inefficient; if so, renegotiation then takes place to an efficient outcome.

${ }^{2}$ see Bolton and Dewatripont (2005), chapter 12.
} 
efficiency is achievable for a wide class of infinite-horizon bargaining games, including most of those commonly found in the literature.

In section 2 we set out the underlying model. Section 3 considers the case in which it is possible for one party to make an initial cash deposit (i.e., financial hostage) and neither party has all the bargaining power. Section 4 considers the case in which a deposit is not feasible or in which one party has all the bargaining power. In Section 5 we consider a finite-horizon version of the model. In this case, efficiency is achievable if the parties can invest in sequence. Section 6 has some brief concluding remarks.

\section{The Model}

There are two risk-neutral players, a buyer $(B)$ and a seller $(S)$. At date 0 (before the game starts) $B$ and $S$ may sign a contract which is enforceable in court (the court is a passive agent in the game). This contract, if any, stipulates payments to be made by $B$ to $S$ as a function of describable and verifiable messages and actions which the players choose later in the game. First we define a game without renegotiation, denoted $G\left(\alpha_{0}\right), \alpha_{0}$ being the contract (possibly the null contract) signed at date 0; the full game played by $B$ and $S$ includes the possibility of renegotiation, as will be described below. $G\left(\alpha_{0}\right)$ begins with an investment stage: at date $1, S$ and $B$ each, simultaneously, choose an amount of investment from the set $[0, \infty)$. S's chosen investment is denoted by $i_{s}$ and $B$ 's by $i_{b}$. The cost of investment $i_{s}$, borne by $S$, is $\psi_{s}\left(i_{s}\right)$ and the cost of $i_{b}$, borne by $B$, is $\psi_{b}\left(i_{b}\right) . \psi_{s}$ and $\psi_{b}$ are both strictly increasing, non-negative functions. After the investments are made a state of the world $\theta$ is randomly realized from a set of possible states $\Theta$. At date $2, S$ and $B$ both observe each other's investments and $\theta$ but the court is not able to observe them either now or later, i.e. $i_{s}, i_{b}$ and $\theta$ are not verifiable. For each $\theta \in \Theta$, there is a set $A(\theta)$ of goods which it is feasible for the parties to trade. At date 3 or later, $S$ chooses which good $a \in A(\theta)$, if any, to produce ${ }^{3}$ (i.e., $S$ can produce only one good at most). After $S$ has produced $a, B$ observes $a$ and decides whether to accept delivery.

\footnotetext{
3 "Produce" is taken to be synonymous with "produce and deliver". If production and delivery were modelled as distinct actions, similar results would apply.
} 
Time is discrete and the horizon is infinite: that is, $S$ can in principle delay for an indefinite time her decision to produce, and, once $S$ has produced, $B$ can delay indefinitely his decision to accept delivery. The set of dates at which it is feasible for $S$ to produce a good is denoted by $T$ and, if $S$ has produced a good at date $t \in T$, the set of dates at which $B$ can accept delivery is denoted by $T^{\prime}(t)$. One possibility, for example, is that $T=\{3,4,5 \ldots\}$ and that $T^{\prime}(t)=\{t+\epsilon, t+2 \epsilon, \ldots\}$ where $0<\epsilon<1$. At any date $t$ at which production has not yet taken place, it is always possible to produce within one period.

The game ends if and when $B$ accepts delivery of $S$ 's good. At any time at or before that there is a contract in force (perhaps the null contract) which may specify payments which the players must make to each other, as functions of verifiable actions taken by them. As mentioned above, as long as the game continues the parties concurrently play a bargaining game over renegotiation of the ruling contract, the details of which we discuss below. If the contract is renegotiated the bargaining continues, so the renegotiated contract may itself be renegotiated, and so on ad infinitum. The verifiable actions are production and acceptance of delivery of goods in $A(\theta)$ as well as transmission of public messages. In other words, the court can tell whether $S$ has produced a good, what that good was (i.e., its name), and whether $B$ accepted delivery; furthermore, there is a set of possible messages which the players can publicly send to each other in such a way that the court can tell that a particular message was sent. For simplicity, we assume that if a contract specifies that a sum $p$ must be paid by, say, $B$ to $S$ when a particular sequence of verifiable actions has been taken, then $p$ is automatically paid at that point. That is, there is no need for the parties to take actions in order to enforce contracts or to make known to the court what the currently ruling contract is (so, implicitly, when a contract is renegotiated the new contract is immediately reported to the court). The investments of the two parties, the state of the world $\theta$ and the bargaining moves (other than acceptance of a new contract) are not observed by the court. ${ }^{4}$ Note that a contract cannot compel either party to take an action, e.g. to produce a specific good $a$ at a specific time.

\footnotetext{
${ }^{4}$ Since the court cannot observe $\theta$, it cannot observe $A(\theta)$, so it does not know what is feasible. Nevertheless, if a feasible good $a \in A(\theta)$ is produced then the court observes that this has happened.
} 
What it can, however, do is, for example, to compel $S$ to pay $B$ a specific sum if $S$ does not produce $a$ by a specific time.

\section{Payoffs}

Suppose that the investments are $\left(i_{s}, i_{b}\right)$, the realized state is $\theta$, at time $t(t \in T)$ $S$ produces good $a \in A(\theta)$, and at time $\tau\left(\tau \in T^{\prime}(t)\right) B$ accepts delivery. Suppose also that $B$ makes a sequence of net payments to $S$ of $p_{1}, p_{2}, p_{3}, \ldots$ at dates $t_{1}, t_{2}, t_{3}, \ldots$ Then $B$ 's payoff is

$$
v\left(i_{s}, i_{b}, \theta, a\right) \delta^{\tau-1}-\sum_{i} p_{i} \delta^{t_{i}-1}-\psi_{b}\left(i_{b}\right)
$$

and $S$ 's payoff is

$$
-c\left(i_{s}, i_{b}, \theta, a\right) \delta^{t-1}+\sum_{i} p_{i} \delta^{t_{i}-1}-\psi_{s}\left(i_{s}\right)
$$

where $v$, the value of the good to $B$, is a non-negative function, $c$, the cost of the good's production to $S$, is a strictly positive function and $\delta \in(0,1)$ is a discount factor (the discount factors are taken to be equal for simplicity). If, given $\left(i_{s}, i_{b}, \theta\right)$ and the above sequence of net payments, there is no production, then their payoffs are respectively $-\sum_{i} p_{i} \delta^{t_{i}-1}-\psi_{b}\left(i_{b}\right)$ and $\sum_{i} p_{i} \delta^{t_{i}-1}-\psi_{s}\left(i_{s}\right)$. Finally, if $S$ produces $a$ at $t$ and $B$ does not accept delivery, then their payoffs are respectively

$$
-\sum_{i} p_{i} \delta^{t_{i}-1}-\psi_{b}\left(i_{b}\right)
$$

and

$$
\sum_{i} p_{i} \delta^{t_{i}-1}-c\left(i_{s}, i_{b}, \theta, a\right) \delta^{t-1}-\psi_{s}\left(i_{s}\right)
$$

Any payment from another source (e.g., the return of a cash deposit) enters the payoff function in the same way as a payment by the other party.

\section{Efficient Actions}

Given $\left(i_{s}, i_{b}, \theta\right) \in \Re_{+} \times \Re_{+} \times \Theta$, let $a\left(i_{s}, i_{b}, \theta\right)$, the efficient good, be a solution to 
the problem

$$
\max _{a \in A(\theta)} \delta^{\gamma} v\left(i_{s}, i_{b}, \theta, a\right)-c\left(i_{s}, i_{b}, \theta, a\right)
$$

where $\gamma$ is the minimum delay between production and acceptance of delivery (for example $\gamma=1$ if, after production at $t$, acceptance of delivery can happen at or after $t+1)$. We assume that, for each $\left(i_{s}, i_{b}, \theta\right) \in \Re_{+} \times \Re_{+} \times \Theta$, a solution to this problem exists. This would be guaranteed if, for example, $A(\theta)$ were a finite set for each $\theta$. We assume also that at least one element of $A(\theta)$ gives a non-negative surplus. This is essentially without loss of generality because we can always define an arbitrarily fixed sum of money as one of the "goods" in $A(\theta)$, and assume that if $S$ delivers this to $B$ then $B$ can accept it (verifiably) without delay. In that case the "produced" good generates a zero surplus. Where the investments and state $\left(i_{s}, i_{b}, \theta\right)$ are understood, we will sometimes denote the value and cost of a good $a \in A(\theta)$ by $v(a)$ and $c(a)$ respectively.

Let

$$
\sigma\left(i_{s}, i_{b}, \theta\right)=\delta^{\gamma} v\left(a\left(i_{s}, i_{b}, \theta\right)\right)-c\left(a\left(i_{s}, i_{b}, \theta\right)\right)
$$

$\sigma\left(i_{s}, i_{b}, \theta\right)$ is therefore the ex post surplus available if the investments and state of the world are $\left(i_{s}, i_{b}, \theta\right)$, gross of investment costs and evaluated at a time when production is feasible. We assume that the expected gross surplus $E_{\theta} \sigma\left(i_{s}, i_{b}, \theta\right)$ exists for each $\left(i_{s}, i_{b}\right)$ and is strictly increasing in $i_{s}$ and $i_{b}$ and that a solution exists for the problem

$$
\max _{i_{s}, i_{b}} \delta^{2} E_{\theta} \sigma\left(i_{s}, i_{b}, \theta\right)-\psi_{s}\left(i_{s}\right)-\psi_{b}\left(i_{b}\right)
$$

subject to $i_{s} \in \Re_{+}, i_{b} \in \Re_{+}$. This would be ensured, for example, if $E_{\theta} \sigma\left(i_{s}, i_{b}, \theta\right)$ were bounded and concave and $\psi_{s}$ and $\psi_{b}$ were unbounded and convex.

We denote the first-best investment levels, the solution to the above problem, by $\left(i_{s}^{*}, i_{b}^{*}\right)$ and we make the following assumption, which guarantees that the problem is not trivial.

$$
E_{\theta} \delta^{2} \sigma\left(i_{s}^{*}, i_{b}^{*}, \theta\right)-\psi_{s}\left(i_{s}^{*}\right)-\psi_{b}\left(i_{b}^{*}\right)>0
$$




\section{Relation to the Literature}

Before completing the description of the game by discussing how renegotiation of contracts may take place, let us digress in order to relate the game to the existing literature. The model is general enough to incorporate as special cases many of the standard models found in the literature on incomplete contracts ${ }^{5}$, some of which are outlined below.

(1) Suppose that there is a single indivisible good to be traded, there is no exogenous uncertainty, the buyer's value for the good $v$ is an increasing function of the buyer's investment and the seller's cost of production $c$ is a decreasing function of the seller's investment. This is a version of the classic hold-up model (for an early treatment of the hold-up problem see, e.g., Williamson (1983)). The model above reduces to this if $\Theta$ and $A$ are singletons, $v\left(i_{s}, i_{b}, \theta, a\right)$ depends only on $i_{b}$ and $c\left(i_{s}, i_{b}, \theta, a\right)$ depends only on $i_{s}$.

(2) Suppose that the model is as in (1) except that $\Theta \subseteq \Re^{n}$ is not a singleton, the buyer's value $v$ varies with $\theta$ and $i_{b}$ but not with $i_{s}$ and the seller's cost $c$ varies with $\theta$ and $i_{s}$ but not with $i_{b}$. Then we have a version of the model of Hart and Moore $(1988)^{6}$. In this case the value and cost, conditional on the investments, are random variables.

(3) Letting $v$ vary with $i_{s}$ as well as $i_{b}$ and $\theta$ and letting $c$ vary with $i_{b}$ as well as with $i_{s}$ and $\theta$ gives, inter alia, a version of the "cooperative" investment model of Che and Hausch (1999). In this case the expectation of the buyer's value for the good may be increased by an increase in the seller's investment and, similarly, the seller's cost of production may be reduced by an increase in the buyer's investment. That is, there are bilateral externalities involved in the choice of investments.

(4) Suppose, as in Segal (1999) and Hart and Moore (1999), that one indivisible good will be traded but that there are many possible versions of it ("widgets") and

\footnotetext{
${ }^{5}$ Although we have been more specific about the timing of production and delivery than many of the papers referred to below.

${ }^{6}$ As we discuss below, however, Hart and Moore make different assumptions about contractibility.
} 
it is not known ex ante which of these widgets should be traded if total surplus is to be maximized. This can be accommodated by letting $A=W$ where $W$ is the set of widgets, and letting $v\left(i_{s}, i_{b}, \theta, a\right)$ depend on $\left(i_{b}, \theta, a\right)$ and $c\left(i_{s}, i_{b}, \theta, a\right)$ on $\left(i_{s}, \theta, a\right)$.

Most of the results in fact would apply equally in a model considerably more general than the one above but we concentrate on this one in order to simplify the exposition. For example, one could allow the parties to produce and consume variable quantities of the good rather than a single indivisible good (as in, for example, Edlin and Reichelstein (1996)). Indeed, one could consider, rather than a model of production and trade, one in which the parties each take general multi-dimensional actions.

Furthermore, the results of this paper extend to the case of multi-dimensional investments as well as to the case in which one or more of the parties is risk-averse.

\section{Contracts}

As noted above, a contract specifies what payments must be made by one party to the other, as a function of events which can be verified by the court. The sets of contracts which the parties may propose in the renegotiation process are referred to as $C_{1}$ (for renegotiation proposals made before $\theta$ is realized at date 2 ) and $C_{2}$ (for proposals made after $\theta$ is realized). We assume that after date 2 the elements of $A$ are describable (this is the assumption commonly made in the incomplete contracts literature) and that $C_{2}$ includes any contract of the following form: "if $S$ produces and delivers $a, B$ must pay a price $p$ to $S$, and if $S$ does not do so by date $\tau$ then $S$ pays a penalty $P$ to $B^{\prime}$, where $\tau$ is a specified date, $p$ and $P$ specified amounts, and $a$ is a specified good. ${ }^{7}$ Such contracts are referred to below as forcing. In effect, such contracts are specific performance contracts, as allowed, for example, by ADR and Nöldeke-Schmidt. Our contractibility assumptions are therefore different from those of Hart and Moore (1988), who assume that the court can observe whether trade took place but not who was responsible for a failure of trade. Unlike contracts

\footnotetext{
${ }^{7}$ Note that the contract names this good. It cannot say "produce the efficient good" because the court, not knowing $\left(i_{s}, i_{b}, \theta\right)$, does not know which one is efficient.
} 
in $C_{2}$, contracts in $C_{1}$ might not be able to include references to the potential goods because it may be that before $\theta$ is realized the goods are not describable. ${ }^{8}$

Contracts may also specify that the parties may send verifiable messages to each other. For example, the contracts described in the next section, which are used to generate the first-best, allow one party to send a verifiable message at or just after time $t=2$ (after $\theta$ is learned) which nominates which good should be produced and what the terms of trade should be. The payments subsequently enforced by the contract will depend on what this message was. We assume that contractual payments cannot depend on verifiable messages sent before the contract was agreed. Finally, we assume in the next section that it is possible at date 0 for one or both parties to deposit a sum of money which will be returned to that party if and only if certain verifiable events have happened. They can also commit to pay such a deposit at a specified date in the future. One can suppose, for example, that the deposit is held by the court, or by a court-appointed lawyer; alternatively, it might be held by the other party. For simplicity, we assume that a deposit can be released only at dates when production of goods is feasible.

\section{Renegotiation}

The parties can always renegotiate the contract, if any, which they signed at date 0 or any subsequent date, and negotiate a contract if none is currently in force. The way the renegotiation works is that as play proceeds proposal decision nodes repeatedly arrive, at each of which one player chooses a contract ${ }^{9}$ (possibly the current ruling contract) from the exogenously given set $C_{1}$ (if $\theta$ has not yet been realized) or $C_{2}$ (if it has) to propose to the other player, and the other player must immediately accept or reject this proposal. If the responding player accepts, then the proposed contract replaces the current ruling contract and, if not, the current contract remains in force.

The disadvantage of a non-cooperative game-theoretic analysis is that the results

\footnotetext{
${ }^{8}$ For discussions of the idea that incompleteness of contracts is related to inability to describe contingencies in advance, and that this indescribability problem leads to inefficiency, see Maskin and Tirole (1999) and Hart and Moore (1999).

${ }^{9}$ Alternatively, we could assume that the proposer offers a menu of contracts for the responder to select from.
} 
may be sensitive to the precise formulation of the extensive form - who can make proposals when, etc. Therefore, rather than setting out a particular extensive form, we will analyze a large class of extensive forms, varying in the fine detail of precisely when proposals can be made, how these dates relate to dates at which production decisions can be made and verifiable messages sent, and how the proposer is chosen. The identity of the proposer at a proposal node is some unspecified function (possibly random) of the history so far, as is the date of the proposal node itself. It is assumed that it is impossible to take any action in between a proposal node and the following response node. We assume also that the game does not have simultaneous moves: for example, it is not possible to make or accept a renegotiation proposal at the same time as either player produces a good or sends a verifiable message. Renegotiation opportunities are frequent in the sense that, for any history, a proposal node will be reached within one period regardless of the continuation strategies played, assuming the game lasts that long. The rules of the renegotiation process are constrained by two assumptions (Assumptions 1 and 2).

Assumption 1 (Weakly Exogenous Renegotiation): The rules governing when proposals can be made, and the identity of the proposer at a proposal node, are independent of past contract proposals and of past and current ruling contracts.

For the purposes of this assumption, deposits are to be understood as elements of contracts - that is, the renegotiation rules are independent of the size or timing of any past deposits. The assumption implies that the parties cannot write contracts which alter the underlying renegotiation game. It still, however, allows for a good deal of flexibility in the modeling of the renegotiation process. For example, the renegotiation protocol (who makes the next proposal and when) may vary with $\theta$, with the production decision made, if any, with past verifiable messages, with past proposal dates and the identity of the proposer at those dates (although not the proposals made), and indeed with the investments made at the outset of the game.

Let the overall game (including investment, production, acceptance of delivery, bargaining moves, etc.) be denoted by $G^{r}\left(\alpha_{0}\right)$, where $\alpha_{0}$ is the initial contract. Thus, 
$G\left(\alpha_{0}\right)$ represents the game in which renegotiation is not possible and so the contract in force is always $\alpha_{0}$, and $G^{r}\left(\alpha_{0}\right)$ represents the game in which renegotiation is possible.

Example: As an illustrative example, consider the following alternating-offers bargaining protocol. Suppose that $\alpha_{0}$ is the null contract and the players cannot renegotiate until after $\theta$ is realized. The set of contracts $C_{2}$ which a player can propose after $t=2$ are the forcing contracts plus contracts of the form 'if $S$ produces the good $a$ then $B$ pays $p$ to $S$ and otherwise no payment is due'. We refer to the latter as option contracts. Suppose that production can take place at any integer time $t \geq 3$ and that, when production has taken place, delivery can be accepted at any later integer time. At date $t=3$ (just before the first production node) $B$ proposes a contract and $S$ immediately either accepts or rejects it. If the contract is rejected by $S$ then, at date $t=4$, if the game has not yet ended, $S$ proposes a contract which $B$ immediately accepts or rejects. If this contract is rejected then $B$ proposes at $t=5$, and so on, proposals and responses always just preceding production dates. While this bargaining proceeds, the players make decisions about whether to produce and, if production has taken place, whether to accept delivery.

This game has a unique subgame-perfect equilibrium continuation outcome after $\theta$ is realized. In this outcome, the parties immediately agree on a contract to trade the efficient good at a price which splits the surplus $\sigma\left(i_{s}, i_{b}, \theta\right)$ according to the Rubinstein shares. At any history at which no contract is in place, if a proposal is rejected, then $S$ does not produce, but waits to the next proposal date. Off the equilibrium path there are multiple equilibrium continuations. To see this, suppose that, as a result of one or more deviations, an option contract has been accepted to produce the efficient good $a$ at a price $p$ such that $c(a)<p<p^{b}$, where $p^{b}$ is the price offered in equilibrium by $B$ (i.e., $\left.p^{b}=\delta(\delta v(a)-c(a))(1+\delta)^{-1}+c(a)\right)$. Then there is an equilibrium continuation in which $S$ does not produce and bargaining continues as if there is no contract, but there is also an equilibrium continuation in which $S$ always produces, if she has not done so yet, at the next production node and $B$ refuses any renegotiation offer involving a price above $p$ (cf. Shaked (1994)). At any history at which some inefficient 
non-equilibrium contract has been proposed and accepted, this contract defines the outside options and hence the shares of the surplus which the players receive in the continuation. If $S$ deviates by producing a good $a$ before agreement is reached on a contract then the surplus over which they subsequently bargain is $v(a)$.

It will be convenient to define a related game, denoted $G^{r}\left(\alpha_{0}, K\right)$, in which the buyer is obliged, at date $t=3$, just before the production node, to deposit a monetary sum $K$ which is returned to the buyer if and when a good is produced. Otherwise, $G^{r}\left(\alpha_{0}, K\right)$ is the same as $G^{r}\left(\alpha_{0}\right)$. Thus, in addition to the surplus which the players can generate by investing and producing, there is a (non-interest-bearing) monetary surplus of value $K$ which is effectively under the joint control of the parties. Therefore, as well as bargaining over what surplus to produce and how to share it, they are also bargaining over how to share the pie $K$ (the respective shares being determined by the negotiated price). The assumption, as in the case of a deposit which is part of an initial or negotiated contract, is that the surplus $K$ can be released only at dates at which production is feasible. The game $G^{r}\left(\alpha_{0}, 0\right)$ is equivalent to $G^{r}\left(\alpha_{0}\right)$.

Before stating Assumption 2 we need some further notation.

Histories The set of finite-length histories of $G^{r}\left(\alpha_{0}, K\right)$ is denoted by $H^{r}\left(\alpha_{0}, K\right)$. The corresponding set of histories of $G\left(\alpha_{0}\right)$ is denoted by $H\left(\alpha_{0}\right)$. A history does not include the sequence of ruling contracts, but the latter can be deduced from a history, given the initial contract. At any stage, both players know the current history, so that any finite-length history defines a continuation subgame. For any finite history, subgame-perfect continuation equilibria are defined in the usual way. Henceforth the term equilibrium will refer to subgame-perfect equilibrium. For any $h \in H^{r}\left(\alpha_{0}, K\right) \cup H\left(\alpha_{0}^{\prime}\right)$, the length of $h$ (i.e., the date of the decision node after the last action in $h)$ is $t(h)$, the contract in force at the end of $h$ is $\alpha(h), a(h)$ is the good that has been produced (if no good has been produced yet then $a(h)=\emptyset$ ) and the investments and (if $t(h) \geq 2$ ) the state are $i_{s}(h), i_{b}(h)$, and $\theta(h)$. Given a history $h \in H^{r}\left(\alpha_{0}, K\right), h^{\prime} \in H^{r}\left(\alpha_{0}, K\right)$ is a history subsequent to $h$ if $h$ and $h^{\prime}$ coincide up to $t(h)$. 
Equivalence of Histories If all renegotiation moves (i.e. proposals and acceptances or rejections) are removed from $\tilde{h} \in H^{r}\left(\alpha_{0}\right)$ then one obtains a history of the game $G\left(\alpha_{0}\right)$. Let $z(\tilde{h})$ refer to this history. That is, $z(\tilde{h})$ is a description of all the nonbargaining moves made since the start of the game. Two histories $h \in H^{r}\left(\alpha_{0}, 0\right)$ and $h^{\prime} \in H\left(\alpha_{0}^{\prime}\right)$ are said to be equivalent if $\alpha(h)=\alpha_{0}^{\prime}$ and $z(h)=h^{\prime}$. Similarly, two histories $h \in G^{r}\left(\alpha_{0}, K\right)$ and $h^{\prime} \in G^{r}\left(\alpha_{0}^{\prime}, K\right)$ are equivalent if $\alpha(h)=\alpha\left(h^{\prime}\right)$ and $z(h)=z\left(h^{\prime}\right)$. Two equivalent histories therefore differ only insofar as the bargaining moves differ. They both, however, have the same ruling contract.

Efficient Outcomes Given any history $h \in H^{r}\left(\alpha_{0}, K\right) \cup H\left(\alpha_{0}^{\prime}\right)$, such that $t(h) \geq 2$, a continuation path is ex post efficient if the following conditions hold: (i) if $a(h)=\emptyset$ then the efficient good $a\left(i_{s}(h), i_{b}(h), \theta(h)\right)$ is produced and accepted at the earliest opportunity; (ii) if $a(h)=a$ then $B$ accepts delivery of $a$ at the earliest opportunity; and (iii) the monetary surplus $K$, if relevant, and the cash deposits, if any, are returned at the earliest opportunity to the players (and there are no payments to third parties). A subgame-perfect continuation equilibrium is efficient if it gives probability one to ex post efficient continuation paths. Note that an efficient continuation path need not be efficient ex ante because the investments made in $h$ may have been suboptimal, or the wrong good may have been produced. A pure strategy profile for the whole game (starting at $t=1$ ) is efficient if the outcome prescribed by the profile has investments $\left(i_{s}^{*}, i_{b}^{*}\right)$, has no payments to third parties and no deposits before date $t=3$, and gives probability 1 to efficient continuation paths after $\theta$ is realized at date $t=2$.

Available Surplus The available surplus at $h$, denoted by $\mu(h)$, is the sum of the continuation payoffs which the two players get in an ex post efficient continuation path (gross of sunk payments, i.e., investment costs, sunk production costs and payments of deposits). Thus, if, for example, no good has yet been produced, deposits totalling $M$ have not yet been returned (but are jointly under the control of the two parties ${ }^{10}$ ), and production is feasible without delay, then the available surplus is $\sigma\left(i_{s}(h), i_{b}(h), \theta(h)\right)+$ $M$.

Our second key assumption about $G^{r}\left(\alpha_{0}, K\right)$ is as follows.

\footnotetext{
${ }^{10}$ For example, the parties have not previously signed the rights away to a third party.
} 
Assumption 2 (Efficient Renegotiation): For some $\lambda_{b} \in(0, \delta)$ the following is true. For any $K \geq 0$ and any history $h \in H^{r}(\emptyset, K)$ such that the investments have been made but there has not yet been a renegotiation proposal opportunity, there is a subgame-perfect continuation equilibrium s such that (i) agreement is reached, at the earliest feasible date after $\theta$ is realized, on an ex post efficient forcing contract; (ii) at every subsequent history $h^{\prime} \in H^{r}(\emptyset, K)$ such that no contract has been negotiated and there is no outstanding contract proposal, agreement is reached on an ex post efficient forcing contract at the earliest feasible date (after $\theta$ is realized); and (iii) B's expected payoff after every such subsequent history $h^{\prime} \in H^{r}(\emptyset, K)$ is less than or equal to $\lambda_{b} \mu\left(h^{\prime}\right)$.

Efficient Renegotiation says the following. Suppose that, just after the investments have been made, there is no contract currently in force and no outstanding contract offer. Then the renegotiation game will have an efficient continuation equilibrium (we may take it that, in this equilibrium, the parties wait until $\theta$ is realized before negotiating an efficient contract). Secondly, at any future date in which no contract has yet been negotiated, and no offer is outstanding, there will be an approximately ${ }^{11}$ efficient continuation equilibrium. Thirdly, at any such stage the buyer's equilibrium share of the available surplus is no more than $\lambda_{b}$. The assumption therefore rules out a bargaining game in which $B$ gets all the surplus (say, because $B$ makes all the offers); we deal with that case separately in Section 4 below (see Proposition 3). The requirement of efficiency is unexceptionable: the normal presumption in a complete information framework is that the parties will negotiate to the Pareto frontier. All that we require here is that the complete information bargaining game has at least one equilibrium with this property. It is easy to check that the assumption is satisfied by the alternating offers game.

\section{Preliminary Results}

In constructing equilibria, one needs to be sure that equilibrium exists in every

\footnotetext{
${ }^{11}$ Efficiency is only approximate because an opportunity to produce may pass before there is a chance to negotiate a contract.
} 
subgame. Since a specific extensive form has not been explicitly defined (including, in particular, the set of allowable contracts) we cannot appeal to standard existence theorems. However, as the following Lemma will imply, existence is guaranteed by Assumptions 1 and 2 .

Lemma 1: Take any history $h^{\prime} \in H^{r}\left(\alpha_{0}, K\right)$ such that a renegotiation proposal has just been accepted. There exists a subgame-perfect equilibrium in the ensuing subgame.

Proof: see Appendix.

The next result says that if in some equilibrium the current contract is always $e x$ post efficient then there is an equilibrium in which this contract is not renegotiated.

Proposition 1: Take any history $h \in H\left(\alpha_{0}\right)$ with $t(h) \geq 2$ for which there is a pure strategy continuation equilibrium $s(h)$ of $G\left(\alpha_{0}\right)$, starting from $h$, such that (i) the continuation outcome path of $s(h)$ is ex post efficient, and (ii) the continuation outcome path of $s(h)$ at every history subsequent to $h$ is ex post efficient. Let $h^{\prime} \in$ $H^{r}\left(\alpha_{0}^{\prime}\right)$ be a history of $G^{r}\left(\alpha_{0}^{\prime}\right)$ in which there is no outstanding offer and which is equivalent to $h$. Then there is a continuation equilibrium $s^{\prime}\left(h^{\prime}\right)$ of $G^{r}\left(\alpha_{0}^{\prime}\right)$ starting from $h^{\prime}$ in which there is no renegotiation and the continuation payoffs for each player in $s(h)$ are equal to the corresponding payoffs in $s^{\prime}\left(h^{\prime}\right)$.

Proof: see Appendix.

The idea of the proof is straightforward. Take the game in which renegotiation is not allowed and consider a history $h$ in which $\theta$ has been realized. Suppose that there is a continuation equilibrium $s$ which is (ex post) efficient, starting at the current date, and which also prescribes efficient continuation play at every subsequent possible history. Then, in the game in which renegotiation is allowed, at a history which is equivalent to $h$, it is open to the players to play exactly as in $s$, as far as production, acceptance of delivery and verifiable messages are concerned, and to refuse to renegotiate unless offered something which gives a higher payoff than $s$ does. 
Since $s$ is always efficient, it would then be impossible to offer a renegotiation which is both profitable to the offeror and acceptable to the responder. Hence there is an equilibrium which is equivalent to $s .^{12}$ For example, suppose that in the alternatingoffers protocol the current contract says that ' $S$ is paid $p$ by $B$ if $S$ produces $a$ at any time, and no payment is due if $a$ is not produced', where $a$ is the efficient good and $p>c(a)$. Then, if renegotiation is not allowed, there is trivially a continuation equilibrium in which, if no production has yet taken place, $S$ produces and delivers $a$ at the first opportunity. And, in the game with alternating-offers renegotiation, there is a continuation equilibrium in which, as long as there has been no renegotiation and no production, $S$ produces $a$ at the next feasible production date and each party always proposes the current contract. For example, if $S$ proposes a higher price, $B$ will reject because he knows that he will get the good for $p$ anyway at the earliest technologically feasible opportunity; if $B$ proposes a lower price, $S$ will reject for a similar reason. Rejecting a renegotiation offer does not destroy surplus because the existing contract already gives rise to efficient behavior. It is likely that Proposition 1 applies in a substantially wider class of bargaining processes than considered here: indeed it should apply in any extensive form which respects the voluntary character of renegotiation.

Though simple, Proposition 1 has strong implications which have been overlooked in the literature. We will see that it implies that bargaining games in the class considered here will have multiple equilibria when there is already a contract a place, if it is an option contract. This is incompatible with the assumption usually made that there is a unique outcome of contract renegotiation.

\section{Efficient Equilibrium}

If the parties do not negotiate a contract before they invest then, in general, the

\footnotetext{
${ }^{12}$ This does not contradict the familiar result that prohibiting renegotiation makes it easier to implement the first-best. Prohibiting renegotiation has bite only if the efficient equilibrium has some continuation equilibrium (necessarily off the equilibrium path) which is inefficient; at such a contingency the parties would renegotiate if they could.
} 
equilibrium outcome of the game will be inefficient - there will be underinvestment. Suppose, for example, that renegotiation takes place according to the alternating offers protocol. There is nothing to be gained by negotiating a contract before $\theta$ is realized. After that, there is an essentially unique equilibrium in which the parties agree a forcing contract to produce the good immediately and the ex post surplus is divided according to the Rubinstein shares. It is clear that the parties, knowing this, will invest less than is socially optimal. This is the standard hold-up problem, and the fact that the seller is able in this model to delay production does not remove it, in the absence of a contract.

Nevertheless, in this section we show that there will be an efficient subgame-perfect equilibrium of the game as long as the initial contract is appropriately designed. Assume that $B$ has liquid wealth of at least $M$ available to leave as a deposit, where $M$ satisfies the inequality

$$
M \geq \max \left[\frac{\psi_{s}\left(i_{s}^{*}\right)}{\delta^{3}\left(1-\lambda_{b}\right)}, \frac{\psi_{s}\left(i_{s}^{*}\right)}{\delta\left(\delta-\lambda_{b}\right)}\right]
$$

In many standard bargaining games (e.g. variants of the alternating offers game) $\lambda_{b}$ can be taken to be approximately $\frac{1}{2}$ if $\delta$ is close to 1 . In that case, the required lower bound is at most approximately $2 \psi_{s}\left(i_{s}^{*}\right)$.

The contract used to generate the first-best equilibrium will be denoted $\alpha^{b}(M)$ and is defined as follows.

$\alpha^{b}(M): B$ commits to deposit $M$ at date 3. At date 2, after learning $\theta, B$ may verifiably specify a good $a_{b}$ and a price $p$. If at any date $t \geq 3, S$ produces good $a_{b}$ then $B$ must pay $p$ to $S$. In that event, $B$ 's deposit is returned to him. If $S$ produces and delivers $a \neq a_{b}, B$ gets the deposit back and neither is obliged to pay anything to the other. If $S$ never produces anything, $B$ does not get his deposit back and neither party is obliged to pay anything to the other.

Note that this contract does not include any descriptions of goods, so that it can be implemented even if the goods are not describable until date 2. It also has the important advantage of simplicity. It combines the features of an option contract 
(the seller has the option, exercisable at any date, of producing at a specified price) with a partial authority contract (the buyer is given the right to set the terms of the option). The party with authority also has to post a bond (in effect, give a hostage); this will have the effect of giving him the incentive to behave in the appropriate way.

\section{Construction of the equilibrium}

First we prove two Lemmas which exhibit two kinds of continuation equilibria obtainable when the contract is $\alpha^{b}(M)$, the first derived from Proposition 1 and the second from Assumption 2.

Lemma 2: Consider any history $h \in H^{r}\left(\alpha^{b}(M), 0\right)$ such that (i) there has been no renegotiation of $\alpha^{b}$, (ii) $B$ has nominated the efficient good $a=a\left(i_{s}(h), i_{b}(h), \theta(h)\right)$ and a price $p \geq c(a)$, (iii) no good has been produced and (iv) there is no outstanding renegotiation offer. There is an efficient continuation equilibrium beginning at $h$ in which the payoffs are $\delta^{\tau}(p-c(a))$ for $S$ and $\delta^{\tau}\left(M+\delta^{\gamma} v(a)-p\right)$ for $B$, where $\tau$ is the time until the next production opportunity.

Proof: If renegotiation were not possible then, at any history in which $B$ has nominated $a$ and price $p \geq c(a)$ there would be a pure strategy continuation equilibrium in which $S$ produces $a$ at the next opportunity, because delay can only reduce her payoff. Similarly, $B$ accepts delivery at the first opportunity since $v(a) \geq 0$ so, if $a$ is the efficient good, this equilibrium is efficient after every history. $h \in H^{r}\left(\alpha^{b}(M), 0\right)$ as described in the statement of the Lemma is equivalent to such a history of $G\left(\alpha^{b}(M)\right)$ so, by Proposition 1, there is an efficient continuation equilibrium beginning at $h$ in which there is no renegotiation and $S$ produces $a$ at the first opportunity, giving the payoffs as described. Q.E.D.

Lemma 3: Consider any history $h \in H^{r}\left(\alpha^{b}(M), 0\right)$ such that (i) $\alpha^{b}$ has not been renegotiated, (ii) the date at which $B$ is supposed to nominate a good has passed and $B$ has either specified a good $a$ and a price $p$ such that $p \leq c(a)+\delta\left(1-\lambda_{b}\right)(M+\sigma(h))$, or else has not specified any good, (iii) $S$ has not yet produced a good, and (iv) there is 
no outstanding offer. There exists an efficient continuation equilibrium $\tilde{s}(h)$ in which $B$ 's payoff $\pi_{b}(\tilde{s}(h))$ satisfies

$$
\pi_{b}(\tilde{s}(h)) \leq \lambda_{b}\left[M+\sigma\left(i_{s}(h), i_{b}(h), \theta(h)\right)\right]
$$

and $S$ 's payoff $\pi_{s}(\tilde{s}(h))$ satisfies

$$
\pi_{s}(\tilde{s}(h)) \geq \delta\left(1-\lambda_{b}\right)\left[M+\sigma\left(i_{s}(h), i_{b}(h), \theta(h)\right)\right]
$$

Proof: see Appendix.

The idea behind Lemma 3 is simple. Suppose that the efficient good has surplus equal to $1(v=1.5$ and $c=0.5)$ and that $B$ has nominated the efficient good and price 0.75 , which would give $S$ a payoff equal to 0.25 . Suppose, moreover, that the renegotiation game is such that if there had been no contract the surplus would have have been split equally, i.e. they would have agreed to produce the efficient good at price 1. Under the contract $\alpha^{b}(M)$, there is an equilibrium in which $S$ holds out for half of the surplus, since she is not obliged to produce. Moreover, the surplus includes the deposit $M$ since, if $S$ does adopt this strategy, $B$ will not get the deposit back until agreement is reached. So, if, say, $M=2$, they will negotiate a new contract in which the efficient good is traded at price 2 and $B$ gets his deposit back.

The continuation equilibria in Lemma 2 and Lemma 3 can be used to construct an ex ante efficient equilibrium, as the next Proposition shows.

Proposition 2: If the initial contract is $\alpha^{b}(M)$ and the renegotiation process satisfies Assumptions 1 and 2 then there is an equilibrium in which both parties invest and trade efficiently. That is, $G^{r}\left(\alpha^{b}(M)\right)$ has an efficient subgame-perfect equilibrium.

Proof: Define a strategy profile $\hat{s}$ as follows. Let $t_{1}$ be the date at which $B$ is supposed to nominate a good.

(a) At date $1, B$ invests $i_{b}^{*}$ and $S$ invests $i_{s}^{*}$.

(b) At any renegotiation proposal node before $t_{1}$ at which no renegotiation proposal 
has been accepted before, the proposer proposes $\alpha^{b}$, i.e., 'no renegotiation'.

(c) At date $t_{1}$, given that there has been no renegotiation so far,

(i) if $S$ has invested $i_{s}^{*}$ and $B$ has invested $i_{b}, B$ specifies the efficient good $a\left(i_{s}^{*}, i_{b}, \theta\right)$ and price $p=c\left(a\left(i_{s}^{*}, i_{b}, \theta\right)\right)+\delta^{-2} \psi_{s}\left(i_{s}^{*}\right)$;

(ii) if the investments were $\left(i_{s}, i_{b}\right)$ for $i_{s} \neq i_{s}^{*}, B$ specifies the efficient good $a\left(i_{s}, i_{b}, \theta\right)$ and price $p=c\left(a\left(i_{s}, i_{b}, \theta\right)\right)$;

(d) Consider three types of history following those in (c) above:

(i) if $B$ has followed the rule given in (c), play the continuation strategy profile specified in Lemma 2.

(ii) if $B$ has deviated from the rule in (c) and has named a good $a$ and price $p \leq$ $c(a)+\delta^{-2} \psi_{s}\left(i_{s}^{*}\right)$ or else has not named any good or price, play the continuation strategy profile specified in Lemma 3.

(iii) if $B$ has deviated in any other way from the rule in (c), play an arbitrary continuation equilibrium of the subgame in which an equivalent contract has just been accepted: this exists by Lemma 1.

(e) At any history before date $t_{1}$ at which a renegotiation proposal has just been accepted for the first time, play an arbitrary continuation equilibrium profile: this exists by Lemma 1.

(f) At any response node before date $t_{1}$, at which no previous renegotiation proposal has been accepted, the responder accepts the proposal if and only if doing so gives the responder strictly higher continuation payoff than does rejecting, where the continuation payoffs are defined implicitly by (b)-(e) above.

This completes the description of $\hat{s}$. The outcome path of $\hat{s}$ is that both players invest the first-best amount, there is no renegotiation, $B$ nominates the efficient good and a price which covers $S$ 's investment cost, and $S$ then produces this good for this price, $B$ 's deposit being returned as soon as it is made. Clearly $\hat{s}$ is efficient.

The continuation strategy profiles described in (d)(i) are equilibria by Lemma 2. Those in (d)(ii) are equilibria by Lemma 3 , since $\delta^{-2} \psi_{s}\left(i_{s}^{*}\right)<\delta\left(1-\lambda_{b}\right)(M+\sigma(h))$ by 
(2). Those in (d)(iii) and (e) are equilibria by construction. The responder at a node as described in (f) cannot profit by a one-shot deviation.

Consider a history $h$ as described in (c)(i). B's payoff if he conforms to $\hat{s}$ is at least

$$
\delta\left(M+\sigma\left(i_{s}^{*}, i_{b}(h), \theta(h)\right)-\delta^{-2} \psi_{s}\left(i_{s}^{*}\right)\right)
$$

since production takes place within at most one period. If $B$ deviates as in (d)(ii) his payoff is at most

$$
\lambda_{b}\left(M+\sigma\left(i_{s}^{*}, i_{b}(h), \theta(h)\right)\right)
$$

which is less by (2), given that $\lambda_{b}<\delta$ and $\sigma \geq 0$. If $B$ deviates as in (d)(iii) $S$ gets at least as much as if $B$ had not deviated, since she has the option of producing and getting at least as high a profit margin; therefore $B$ cannot benefit. At a history $h$ as described in (c)(ii), $B$ obtains all the surplus if he conforms to $\hat{s}$ and he cannot deviate in such a way that $S$ gets a negative continuation payoff. Therefore deviation is not profitable.

At a renegotiation node as described in (b) the continuation equilibrium is efficient if there is no renegotiation, and unaffected by any rejected proposal. Therefore, by (f), a proposal will only be accepted if it strictly reduces the payoff of the proposer and so the behaviour described in (b) is optimal.

It is optimal for $S$ to invest $i_{s}^{*}$ because, if she does so, her net payoff, given any $\theta$, will be $\delta^{2}\left(p-c\left(a\left(i_{s}^{*}, i_{b}^{*}, \theta\right)\right)\right)-\psi_{s}\left(i_{s}^{*}\right)=0$ by (a), (b), (c)(i) and (d), whereas if she deviates, she can get at most zero, by (b), (c)(ii) and (d). Now consider B's investment decision. If $B$ invests $i_{b}$, then his expected payoff is

$$
\delta^{2} E_{\theta} \sigma\left(i_{s}^{*}, i_{b}, \theta\right)-\psi_{s}\left(i_{s}^{*}\right)-\psi_{b}\left(i_{b}\right)+\delta^{2} M
$$

since at date 3 he will get all the available surplus (including the return of his deposit) less the price $\psi_{s}\left(i_{s}^{*}\right)$ (in present value terms) which he will pay for the efficient good. 
Since $i_{b}^{*}$ maximizes the net social surplus, this is his optimal choice.

This establishes that $\hat{s}$ is an equilibrium. Q.E.D.

The logic of the argument ${ }^{13}$ is that, given initial contract $\alpha^{b}(M)$, there will be multiple equilibria in the renegotiation game which is played after the investments have been made and the state of the world is known. These equilibria can then be exploited (i) to punish $S$ if she does not invest the efficient amount at date 1, and (ii) to punish $B$ if he tries to improve his position by abusing his authority. The role of the deposit is to increase the size of the possible punishment. ${ }^{14} B$ has an incentive to invest the efficient amount because the contract makes him the residual claimant. Note that since the game is not repeated (production takes place at most once) this result is not due to Folk Theorem considerations.

The result is very different from those found in the hold-up literature. The reason for the difference is that previous papers assume that there is a unique renegotiation outcome (which appears to be consistent with the fact that many standard bargaining games have a unique equilibrium). The argument here is that, given a certain type of initial contract, there will be multiple equilibria in most non-cooperative infinite-horizon models of renegotiation. There is an important difference between the situation under study here and the one studied in standard bargaining models: there is a pre-existing contract. Moreover, this contract is so constructed that one party is allowed, unilaterally, to realize the efficient surplus at any time at which it is technologically feasible to do so. In the usual models of bargaining, neither side can create the surplus unless the parties have reached an agreement; in the case studied here, by contrast, they have already reached a legally enforceable agreement about how to split the surplus and one party has been given an option to trigger this outcome at any date.

Our assumptions about the renegotiation process have ruled out games with con-

\footnotetext{
${ }^{13}$ Since $S$ 's payoff in equilibrium is zero, her equilibrium strategy is weakly dominated by one in which she invests zero. However, a slight adjustment to the strategies (giving $S$ a small positive surplus) gives an equilibrium in undominated strategies.

${ }^{14}$ The contracts in ADR also use deposits to alter the bargaining powers. In their case, however, the idea is to drive one party's bargaining power to zero.
} 
tinuous time, simultaneous moves and open offers (that is, a responder cannot wait before deciding whether to accept an offer of a new contract), as well as games in which the parties have to decide which contract to show to the court. It seems probable, however, that the results above are robust to some, at least, of these extensions. A renegotiation game in which the equilibrium outcome is unique (when the contract is $\alpha^{b}$ ) would have to have the feature that at some date $t$ the seller is not able unilaterally to exercise the option and so realize the surplus $\sigma$ in the current period, but she can offer $B$ an agreement generating a joint surplus at $t$. For example, in the Rubinstein model uniqueness of equilibrium derives from the property that if a responder accepts a proposal then surplus is created at $t$, but if this proposal is rejected then no surplus can be created until some time after $t$. But if there is no technological obstacle to producing at $t$ (and how otherwise could $S$ offer a payoff pair at $t$ ?) there can be no reason why the option could not be exercised at $t$. Once one allows exercise of the option at any date at which surplus could be realized under a renegotiated contract, one gets equilibria ${ }^{15}$ of the type described in Proposition 2.

The equilibrium of Proposition 2 is not unique, so that $G\left(\alpha^{b}\right)$ implements the first-best only in a weak sense. The weak notion of implementation is less commonly used in contract theory than the strong notion and so it may require some justification. One reason for allowing a multiplicity of equilibria is that the parties, in the initial unmodeled negotiation which leads to the contract $\alpha^{b}(M)$, can be regarded also as agreeing the strategies which they will play in the subsequent game. In other words, their agreement can be thought of as having two parts: a legally enforceable part $\alpha^{b}(M)$ and a part which is not legally enforceable (their strategies in the game $G^{r}\left(\alpha^{b}(M)\right)$ or, conceivably, an agreement about how much payoff each party should end up with. The agreement as a whole can be regarded as convincing (and so to describe their subsequent behavior) if the part which is not legally enforceable is selfenforcing, i.e., if it forms a subgame-perfect equilibrium. The literature on relational

\footnotetext{
${ }^{15}$ Another extensive form bargaining game in which there are multiple equilibria is one in which the players have the option of leaving the relationship at any time. Such an equilibrium would, however, not be renegotiation-proof because after a party has opted out they could create surplus by opting back in.
} 
contracting (Macleod and Malcomson (1989), Levin (2003)) takes a similar approach. See also the notion of partial contracting in Aghion, Dewatripont and Rey (2002).

We have noted that one advantage of the efficient contract $\alpha^{b}(M)$ is its simplicity. It is also, compared with the mechanisms often found in the classical implementation literature, relatively realistic. A further advantage is that it is not sensitive to the details of the cost functions, the renegotiation process, or the way in which future surplus depends on the investments. In the ADR analysis, by contrast, the optimal contract includes a default outcome which has to be calibrated in such a way that at the seller's first-best investment her marginal investment cost is equal to the marginal benefit of investment, assuming the default outcome happens. In general, as pointed out by Maskin and Tirole (1999), the incomplete contracts literature assumes that the parties, even if they cannot specify future outcomes in a contract, are able to foresee how different possible physical outcomes map into payoffs; in other words they can do dynamic programming. In the set-up considered here, however, the parties only need to know what the investments that they want to induce are, and an upper bound on their cost. The same contract will support these investments for a wide range of bargaining powers, cost functions, and specifications of the future environment.

\section{Liquidity Constrained Agents}

The contract $\alpha^{b}(M)$ used above to obtain the first-best equilibrium (Proposition 2) required the buyer to make a deposit. Suppose now that it is not possible to use deposits because of liquidity constraints, or for some other reason. Under what circumstances is it possible to achieve the first-best? It turns out that it will still be possible if the surplus is large enough relative to the size of the investments or if the bargaining powers are relatively unequal (in particular if one party has all the bargaining power full efficiency is achievable).

Suppose that a version of Assumption 2 holds for $S$, with parameter $\lambda_{s} \in(0, \delta)$. That is, the game without a contract has an efficient continuation equilibrium and 


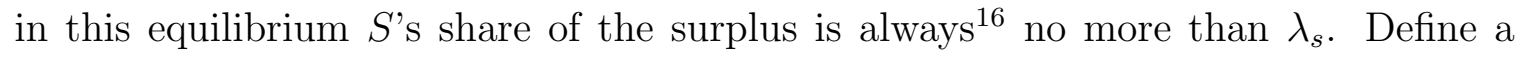
contract $\alpha^{s}(0)$, symmetric to $\alpha^{b}(0)$, as follows.

$\alpha^{s}(0)$ : At date 2, after learning $\theta, S$ may specify a price $p$ and good $a$. If she does not do so, there are no contractual payment obligations for either party. If at date $t=3, S$ produces the nominated good $a$ and $B$ subsequently accepts delivery then $B$ must pay $p$ to $S$, while if $B$ never accepts delivery then neither party is obliged to pay anything to the other. If $S$ does not produce the nominated good at date 3 then she pays a large penalty to $B$.

$S$ is not required to make any deposit under this contract. Like $\alpha^{b}$, it gives a nonexpiring option to one party (in this case the option to accept delivery at a specified price) and it gives the other party the right to set the terms of the option (i.e. the price). We then have the following result.

Proposition 3: (i) Suppose that, for all $i_{b} \leq i_{b}^{*}$,

$$
E_{\theta} \sigma\left(i_{s}^{*}, i_{b}^{*}, \theta\right)-\psi_{s}\left(i_{s}^{*}\right)-\psi_{b}\left(i_{b}^{*}\right)>\lambda_{b} E_{\theta} \sigma\left(i_{s}^{*}, i_{b}, \theta\right)-\psi_{b}\left(i_{b}\right)
$$

Then, if $\delta$ is close enough to $1, G^{r}\left(\alpha^{b}(0)\right)$ has an efficient equilibrium.

(ii) Suppose that, for all $i_{s} \leq i_{s}^{*}$,

$$
E_{\theta} \sigma\left(i_{s}^{*}, i_{b}^{*}, \theta\right)-\psi_{s}\left(i_{s}^{*}\right)-\psi_{b}\left(i_{b}^{*}\right)>\lambda_{s} E_{\theta} \sigma\left(i_{s}, i_{b}^{*}, \theta\right)-\psi_{s}\left(i_{s}\right)
$$

Then, if $\delta$ is close enough to $1, G^{r}\left(\alpha^{s}(0)\right)$ has an efficient equilibrium.

Proof: see Appendix.

Note that (4) holds if

$$
E_{\theta} \sigma\left(i_{s}^{*}, i_{b}^{*}, \theta\right)>\frac{\psi_{s}\left(i_{s}^{*}\right)+\psi_{b}\left(i_{b}^{*}\right)}{1-\lambda_{b}}
$$

\footnotetext{
${ }^{16}$ At least if there is no outstanding offer.
} 
since $E_{\theta} \sigma\left(i_{s}^{*}, i_{b}^{*}, \theta\right) \geq E_{\theta} \sigma\left(i_{s}^{*}, i_{b}, \theta\right)$ for all $i_{b} \leq i_{b}^{*}$. In the alternating-offers game, $\lambda_{b}$ and $\lambda_{s}$ are both approximately equal to 0.5 if $\delta$ is close to 1 . In that case Proposition 3 implies that the first-best is achievable if the first-best gross expected surplus is more than twice the cost of the optimal investments. This condition becomes less restrictive as the bargaining powers become more asymmetric. For example, if $B$ has all the bargaining power $\left(\lambda_{s}=0\right)$ then, by $(1)$,

$$
E_{\theta} \sigma\left(i_{s}^{*}, i_{b}^{*}, \theta\right)>\frac{\psi_{s}\left(i_{s}^{*}\right)+\psi_{b}\left(i_{b}^{*}\right)}{1-\lambda_{s}}
$$

is satisfied, so, by Proposition 3(ii), $G^{r}\left(\alpha^{s}(0)\right)$ has an efficient equilibrium if $\delta$ is high. ${ }^{17}$

In the equilibrium of Proposition 3(i) both parties invest efficiently and $B$ then nominates the efficient good and gives $S$ a profit margin of

$$
\frac{\psi_{s}\left(i_{s}^{*}\right) \sigma\left(i_{s}^{*}, i_{b}^{*}, \theta\right)}{\delta^{2} E_{\theta} \sigma\left(i_{s}^{*}, i_{b}^{*}, \theta\right)}
$$

which, in expectation, compensates $S$ for her investment. If $S$ underinvests then $S$ is punished by getting zero gross profit. As in Proposition 2, $B$ is punished for making the wrong nomination by a renegotiation of the shares of the surplus, but in this case he is punished in the same way for underinvesting. (4) ensures that this punishment is strong enough. The equilibrium of Proposition 3(ii) is symmetric. In equilibrium $S$ nominates the efficient good and a price which gives $B$ enough surplus to compensate him, in expectation, for his investment. If $S$ deviates then a lower price is negotiated.

Proposition 3 enables us to draw some conclusions about which party should be given authority. In the model of the previous section, with either party able to make a sufficiently high deposit, authority could be given to either party since a result analogous to Proposition 2 can be established with initial contract $\alpha^{s}(M)$, which is the same as $\alpha^{s}(0)$ except that $S$ makes a deposit of $M$ which is returned only when $B$ accepts $S$ 's good. However, when neither party is able to make a deposit, (4) and (5) show that the buyer should have authority if $\lambda_{b}$ is low or when $\psi_{s}\left(i_{s}^{*}\right)$ is low

\footnotetext{
${ }^{17}$ In fact, as the proof shows, $\delta$ does not have to be high in this case.
} 
and, conversely, $S$ should have authority when $\lambda_{s}$ or $\psi_{b}\left(i_{b}^{*}\right)$ is low. If the seller has a sufficiently low cost of optimal investment then the buyer will have a lower incentive to underinvest and take a share $\lambda_{b}$ instead of compensating the seller for her investment and taking the residual surplus. If the buyer has a low bargaining power then the threat of renegotiation if he deviates is stronger, so giving him authority is less costly.

\section{A Finite Horizon Model with Sequential Investments}

The argument in Sections 3 and 4 shows that an efficient equilibrium will exist, given the right initial contract, if the seller can indefinitely delay production. In many situations, however, indefinite delay is not possible: production has to take place by some fixed finite date, or else all possibility of surplus is lost. Even in this case, it is possible to induce the first-best investments if the two parties can invest sequentially i.e., one invests first and the other then invests after observing the first agent's choice. This, as above, is despite the fact that the environment may be complex and there may be direct externalities. In this section we briefly sketch the argument.

Suppose, then, that, instead of having to invest simultaneously at date 1 , the two players are able to invest one after the other. Each can either (i) invest at date 1 or (ii) having observed whether (and how much) the other player invested at date 1, invest at date $1+\varepsilon$, for $1>\varepsilon>0$. There are no further opportunities to invest. Suppose also that if production does not take place at date $t=3$ then there is no further production opportunity and so no surplus is created; similarly, if $B$ does not accept delivery of a produced good at $3+\varepsilon$ then no value is created (the good perishes). Assume that there is no discounting. In every other respect the game is as in Section 2 ; in particular there are frequent opportunities to renegotiate the contract.

Consider first the following contract: ' $S$ names a price $p$ after $\theta$ is realized and produces a good of her choice. $B$ then has the option of accepting delivery at price $p$ or not accepting delivery, in which case he does not have to pay anything.' This contract will give $S$ all the available surplus. All $S$ has to do is produce the efficient good and name a price equal to $B$ 's valuation of it. $B$ 's best choice is to accept 
delivery at date $t+\varepsilon$ since the alternative would give him zero; knowing this, $S$ will reject any renegotiation offer by $B$. At the same time, $B$ 's option not to buy ensures that he gets at least zero, so we have a unique equilibrium. We can refer to this as the 'seller-authority' contract. Similarly, there is a 'buyer-authority' contract according to which $B$ (after the realization of $\theta$ ) names a good and a price and $S$ decides whether or not to produce this good at this price. Again, $S$ will be obliged to produce at date 3 at cost and so the unique equilibrium is efficient, in this case giving all the surplus to $B$.

Now we use an idea employed by Demski and Sappington (1991) and Hermalin and Katz (1991) in a principal-agent model and by Nöldeke and Schmidt (1998) in a property-rights model. Suppose that the initial contract has the following form. We start with a 'buyer-authority' contract, but at or after the first investment stage $B$ can name a price $q$ at which $S$ has the right to buy $B$ out and change the contract to a 'seller-authority' one. $S$ 's option to buy expires after the last date at which $S$ can invest and before date 2 , when $\theta$ is realized. In this game every subgame-perfect equilibrium is efficient. In equilibrium, $B$ invests $i_{b}^{*}$ in period 1 , while $S$ invests nothing. $B$ names price $q$ equal to the maximum expected surplus $E_{\theta} \sigma\left(i_{s}^{*}, i_{b}^{*}, \theta\right) . S$ then finds it optimal to pay $q$ and invest $i_{s}^{*}$ because she will then be the residual claimant. $B$ 's initial investment of $i_{b}^{*}$ is optimal for him because he will be able to extract all the expected surplus through the option price, so he is the residual claimant at the outset. There is no renegotiation in equilibrium because the continuation equilibrium is always efficient. ${ }^{18}$

The idea of using options in this way is not new, but it seems not to have been noticed in the literature that if sequential investment is possible, this device solves the hold-up problem in very general settings, including those in which contracts have appeared to be powerless. ${ }^{19}$ Che and Sakovics (2003) show that, in the simplest

\footnotetext{
${ }^{18}$ This construction requires the existence of a date at which it is too late to invest but $\theta$ is not yet known and for this date to be known in advance (since the option expires at such a date). Suppose instead that it is known that such a date will exist, it is not known ex ante when it will be, but the buyer will know it when it arrives. In that case the contract can stipulate that the option has no expiry date and that the buyer can cancel the option at any time. He will cancel it if $S$ has failed to exercise it when the final investment date has passed.

${ }^{19}$ The approach taken here can encompass all types of surplus-enhancing investments, not just, as
} 
kind of hold-up setting, efficiency is achievable if there are repeated opportunities to invest. The result in this section shows that if the parties can write and trade simple option contracts then the same applies in more general settings, and that only two investment periods are required.

\section{Concluding Remarks}

We have analyzed a general buyer-seller hold-up model in which there is symmetric information and ex post contractible production and trade. The main result is that if an explicitly non-cooperative approach is taken to the renegotiation process (allowing the seller to delay production) then there will generally be an efficient equilibrium even in those settings (direct externalities, complex environments) in which it has been thought that contracts can achieve nothing. Furthermore, the contracts used to generate the efficient equilibrium are simple and robust (in the sense that they do not have to be finely adapted to the cost and payoff functions), and they are similar to contracts which are frequently observed in practice.

\section{APPENDIX}

Proof of Lemma 1: Consider a history $\tilde{h} \in H^{r}(\emptyset, K)$ which is the same as $h^{\prime}$ in every respect except, possibly, bargaining moves. In $\tilde{h}$ there are no accepted renegotiation proposals until the final two nodes, at which point $\alpha\left(h^{\prime}\right)$ is proposed and accepted. Thus, $\tilde{h}$ and $h^{\prime}$ are equivalent: they have the same investments, $\theta$, verifiable history and ruling contract. Furthermore, by Assumption 1, the renegotiation game after $h^{\prime}$ is the same as the renegotiation game after $\tilde{h}$. Therefore the subgame beginning at $h$ is the same as the subgame beginning at $\tilde{h}$. But $\tilde{h}$ is subsequent to a history $h$ as described in Assumption 2. There is, by Assumption 2, a subgame-perfect equilibrium in the subgame beginning at $h$; the profile induced by this equilibrium in the game following $\tilde{h}$ is then a subgame-perfect equilibrium of this game, hence a in Nöldeke and Schmidt (1998), investments in physical assets. 
subgame-perfect equilibrium in the game starting at $h^{\prime}$. Q.E.D.

Proof of Proposition 1: Define a continuation strategy profile $s^{\prime}\left(h^{\prime}\right)$ as follows. Consider three types of subgame (histories subsequent to $h^{\prime}$ ): (i) those in which there has been no change of contract since $h^{\prime}$ (so the contract is $\alpha_{0}$ ) and there is no outstanding offer; (ii) those in which there has been no change of contract since $h^{\prime}$ but a new contract has just been proposed; and (iii) those at which a renegotiation proposal has just been accepted for the first time since $h^{\prime}$. For any subgame of type (iii), there exists a subgame-perfect equilibrium by Lemma 1. Select an arbitrary such equilibrium profile and set $s^{\prime}\left(h^{\prime}\right)$ equal to this profile in this subgame. For histories of type (i), $s^{\prime}\left(h^{\prime}\right)$ is defined as 'play according to $s$ at non-bargaining nodes, and at proposal nodes always propose $\alpha_{0}$ (i.e., no renegotiation)'. For any history of type (ii), the continuation payoff of the responder if he accepts the proposal is determined by (iii) above, and, if he rejects the proposal, by (i) above (i.e., the payoffs are given by $s)$. At this history, the responder's action specified by $s^{\prime}\left(h^{\prime}\right)$ is: 'accept if and only if the continuation payoff for 'accept' is higher than that for 'reject' '. This defines $s^{\prime}\left(h^{\prime}\right)$. If the players adopt this profile, there is no renegotiation and the outcome is the same as the outcome of $s$. By construction, $s^{\prime}\left(h^{\prime}\right)$ forms an equilibrium after any renegotiation. Clearly, neither player can benefit before that by a one-shot deviation at a response node. To show that $s^{\prime}\left(h^{\prime}\right)$ is an equilibrium, we need to show that neither player can deviate profitably at a history of type (i). No deviation which does not involve a renegotiation proposal can be profitable because $s$ is an equilibrium in the game without renegotiation. Consider a deviation in which a player makes a proposal not equal to $\alpha_{0}$ (i.e., proposes a new contract). Without this deviation, this player's continuation payoff would be that corresponding to $s$. If the proposer benefits by this deviation, it must be that the responder is worse off, by efficiency of $s$ in the continuation. But, since the responder can reject the proposal and thus obtain the continuation payoff corresponding to $s$, that is impossible. This shows that $s^{\prime}\left(h^{\prime}\right)$ is an equilibrium. Q.E.D.

Proof of Lemma 3: Take a history $h^{\prime} \in H^{r}(\emptyset, M)$ which is equivalent to $h$, except 
that there has been no renegotiation, so that $\alpha\left(h^{\prime}\right)=\emptyset$. Thus, the investments, state and all verifiable actions (including the deposit of $M$ at date 3 ) are the same as in $h$. By Assumption 1, the game-form after $h$ is the same as that after $h^{\prime}$. Take a continuation profile which leads, at some date $t$, to the same contract (not equal to $\alpha^{b}(M)$ ), whether the starting point is $h$ or $h^{\prime}$. Then the continuation payoff pair will be the same at those two eventualities (since the continuation game-form, continuation strategies, ruling contract, payoff structure, and verifiable history will all be the same). The only difference between the subgame at $h$ and the subgame at $h^{\prime}$ is that, as long as the current contract has not been renegotiated, in the former $S$ gets paid $p$ if she produces $B$ 's nominated good, whereas in the latter she gets paid nothing for producing any good, although in both cases $B$ gets his deposit of $M$ returned in that event.

By Assumption 2, there exists a continuation equilibrium profile $s^{\prime}\left(h^{\prime}\right)$, starting at $h^{\prime}$, in which agreement is reached at the earliest opportunity on an efficient forcing contract and in which $B$ 's share of the available surplus is no more than $\lambda_{b}$ at this point and also at any subsequent point at which no contract has been negotiated and there is no outstanding contract offer.

Since the game-forms at $h$ and at $h^{\prime}$ are identical, $s^{\prime}\left(h^{\prime}\right)$ is a valid continuation strategy profile for the game $G^{r}\left(\alpha^{b}(M), 0\right)$, beginning at $h$. Let $\tilde{s}(h)=s^{\prime}\left(h^{\prime}\right)$. Under this profile, $S$ does not produce until a new contract is negotiated (otherwise her payoff in $G^{r}(\emptyset, M)$ would be zero, contradicting Assumption 2). I will show that it is an equilibrium profile. Clearly it is an equilibrium after any renegotiation because, as noted above, the subgame is then the same as the corresponding subgame in $G^{r}(\emptyset, M)$. Since future play will be given by $s^{\prime}\left(h^{\prime}\right)$, the payoffs from rejecting a renegotiation offer will also be the same as in $G^{r}(\emptyset, M)$, so the acceptance rules given by $s^{\prime}\left(h^{\prime}\right)$ are always optimal. It is only necessary to show that neither player can deviate profitably at a history $h^{\prime \prime}$ when there has been no renegotiation and there is no outstanding offer. If the deviation does not involve producing $B$ 's nominated good then it cannot be profitable because, if it were, then the same deviation would be profitable in $G^{r}(\emptyset, M)$, contradicting the fact that $s^{\prime}\left(h^{\prime}\right)$ is an equilibrium. If 
$S$ produces $B$ 's nominated good $a$ then $S$ gets a payoff of $p-c(a)$, whereas if she conforms to the strategy given by $s^{\prime}\left(h^{\prime}\right)$ she gets at least $\left(1-\lambda_{b}\right) \mu\left(h^{\prime \prime}\right)$ by Assumption 2. But $p-c(a) \leq \delta\left(1-\lambda_{b}\right)\left[M+\sigma\left(i_{s}\left(h^{\prime \prime}\right), i_{b}\left(h^{\prime \prime}\right), \theta\left(h^{\prime \prime}\right)\right)\right] \leq\left(1-\lambda_{b}\right) \mu\left(h^{\prime \prime}\right)$ so producing $a$ is worse for $S$ than not doing so. Therefore $\tilde{s}(h)$ is an equilibrium. The bounds on the equilibrium payoffs follow from Assumption 2 and the fact that at most one period can elapse before renegotiation and production (and the return of the deposit) take place. Q.E.D.

Proof of Proposition 3(i) Consider a strategy profile $s^{1}$ as follows (as before, $t_{1}$ is the date at which the good is nominated).

(a) At date 1, $B$ invests $i_{b}^{*}$ and $S$ invests $i_{s}^{*}$.

(b) At any renegotiation proposal node before $t_{1}$ at which no renegotiation proposal has been accepted before, the proposer proposes $\alpha^{b}(0)$, i.e., 'no renegotiation'.

(c) At date $t_{1}$, given that there has been no renegotiation so far,

(i) If $S$ has invested $i_{s}^{*}$ and $B$ has invested $i_{b} \geq i_{b}^{*}, B$ specifies the efficient good $a\left(i_{s}^{*}, i_{b}, \theta\right)$ and price

$$
p=c\left(a\left(i_{s}^{*}, i_{b}, \theta\right)\right)+\frac{\psi_{s}\left(i_{s}^{*}\right) \sigma\left(i_{s}^{*}, i_{b}, \theta\right)}{E_{\theta} \delta^{2} \sigma\left(i_{s}^{*}, i_{b}^{*}, \theta\right)} .
$$

If $B$ has followed this rule, the continuation strategy profile is as specified in Lemma 2. If $B$ has deviated by making no nomination, or by nominating an inefficient good, or by nominating a profit margin for $S$ less than

$$
\frac{\psi_{s}\left(i_{s}^{*}\right) \sigma\left(i_{s}^{*}, i_{b}, \theta\right)}{E_{\theta} \delta^{2} \sigma\left(i_{s}^{*}, i_{b}^{*}, \theta\right)}
$$

the continuation strategy profile is as specified in Lemma 3. If $B$ has deviated by nominating a higher profit margin, play an arbitrary continuation equilibrium of the subgame in which an equivalent contract has just been accepted: this exists by Lemma 1.

(ii) If the investments were $\left(i_{s}, i_{b}\right)$ for $i_{s} \neq i_{s}^{*}, B$ specifies the efficient good $a\left(i_{s}, i_{b}, \theta\right)$ and price $p=c\left(a\left(i_{s}, i_{b}, \theta\right)\right)$. If $B$ has followed this rule, the contin- 
uation strategy profile is as specified in Lemma 2. If $B$ has deviated, play an arbitrary continuation equilibrium.

(d) At date $t_{1}$, given that there has been no renegotiation so far, $S$ has invested $i_{s}^{*}$ and $B$ has invested $i_{b}<i_{b}^{*}$ :

(i) if $B$ has nominated no good, or has nominated a good and a profit margin for $S$ less than or equal to $\delta\left(1-\lambda_{b}\right) \sigma$, play the continuation strategy profile specified in Lemma 3.

(ii) if $B$ has nominated a profit margin for $S$ greater than $\delta\left(1-\lambda_{b}\right) \sigma$, play an arbitrary continuation equilibrium profile.

(iii) given (i) and (ii) above, $B$ chooses a good and price (or no nomination) to maximize his expected continuation payoff.

(e) At any history before date $t_{1}$ at which a renegotiation proposal has just been accepted for the first time, play an arbitrary continuation equilibrium profile: this exists by Lemma 1.

(f) At any response node before date $t_{1}$, at which no previous renegotiation proposal has been accepted, the responder accepts the proposal if and only if doing so gives the responder strictly higher continuation payoff than does rejecting, where the continuation payoff is defined implicitly by (b)-(e) above.

This describes the profile $s^{1}$. Note that, for high $\delta$,

$$
\frac{\psi_{s}\left(i_{s}^{*}\right) \sigma\left(i_{s}^{*}, i_{b}, \theta\right)}{E_{\theta} \delta^{2} \sigma\left(i_{s}^{*}, i_{b}^{*}, \theta\right)}<\delta\left(1-\lambda_{b}\right) \sigma\left(i_{s}^{*}, i_{b}, \theta\right)
$$

by (4) (with $i_{b}=i_{b}^{*}$ ). In (c)(i), if $B$ conforms to $s^{1}, S$ gets (valued at a production node)

$$
\frac{\psi_{s}\left(i_{s}^{*}\right) \sigma\left(i_{s}^{*}, i_{b}, \theta\right)}{E_{\theta} \delta^{2} \sigma\left(i_{s}^{*}, i_{b}^{*}, \theta\right)}
$$

If he makes no nomination, or nominates a lower margin, $S$ gets at least $\delta(1-$ $\left.\lambda_{b}\right) \sigma\left(i_{s}^{*}, i_{b}, \theta\right)$, which is greater by (6), so $B$ must be worse off. He must also be worse off if he nominates a higher margin.

In (c)(ii), $B$ gets all the surplus if he conforms. Since $S$ must get a non-negative 
continuation payoff after any deviation, $B$ cannot profitably deviate.

The continuation profile after (c)(i) is an equilibrium by (6). The continuations described in (d) are clearly equilibria.

$S$ 's expected ex post expected surplus if she invests $i_{s}^{*}$, discounted to date 1 , is $\psi_{s}\left(i_{s}^{*}\right)$ as in the proof of Proposition 2, so that $i_{s}^{*}$ is the optimal choice for her.

It remains to show that it is optimal for $B$ to invest $i_{b}^{*}$.

If $i_{b} \geq i_{b}^{*}$ then $B$ 's expected payoff is

$$
\begin{gathered}
E_{\theta} \delta^{2} \sigma\left(i_{s}^{*}, i_{b}, \theta\right)-\psi_{b}\left(i_{b}\right)-\frac{\delta^{2} \psi_{s}\left(i_{s}^{*}\right) E_{\theta} \sigma\left(i_{s}^{*}, i_{b}, \theta\right)}{\delta^{2} E_{\theta} \sigma\left(i_{s}^{*}, i_{b}^{*}, \theta\right)} \\
\leq E_{\theta} \delta^{2} \sigma\left(i_{s}^{*}, i_{b}, \theta\right)-\psi_{b}\left(i_{b}\right)-\psi_{s}\left(i_{s}^{*}\right)
\end{gathered}
$$

since $\sigma$ is increasing in $i_{b}$, and, if he invests $i_{b}^{*}$ his payoff is

$$
E_{\theta} \delta^{2} \sigma\left(i_{s}^{*}, i_{b}^{*}, \theta\right)-\psi_{s}\left(i_{s}^{*}\right)-\psi_{b}\left(i_{b}^{*}\right)
$$

which maximizes the RHS of the above inequality, so $i_{b}^{*}$ is optimal for $B$ in this range. If $i_{b}<i_{b}^{*}$ then $S$ gets, ex post, at least

$$
E_{\theta} \delta^{3}\left(1-\lambda_{b}\right) \sigma\left(i_{s}^{*}, i_{b}, \theta\right)
$$

so $B$ gets, ex ante, at most

$$
\begin{gathered}
E_{\theta} \delta^{2} \sigma\left(i_{s}^{*}, i_{b}, \theta\right)-E_{\theta} \delta^{3}\left(1-\lambda_{b}\right) \sigma\left(i_{s}^{*}, i_{b}, \theta\right)-\psi_{b}\left(i_{b}\right) \\
=E_{\theta} \delta^{2}\left(1-\delta+\lambda_{b} \delta\right) \sigma\left(i_{s}^{*}, i_{b}, \theta\right)-\psi_{b}\left(i_{b}\right) .
\end{gathered}
$$

If he does not deviate, he gets

$$
E_{\theta} \delta^{2} \sigma\left(i_{s}^{*}, i_{b}^{*}, \theta\right)-\psi_{s}\left(i_{s}^{*}\right)-\psi_{b}\left(i_{b}^{*}\right)
$$

which is greater by (4), for high $\delta$. Therefore it is optimal for him to invest $i_{b}^{*}$. Q.E.D. 
Proof of Proposition 3(ii) (a) Consider a history at which there has been no renegotiation, there is no outstanding offer, $S$ has named a price $p$ and good $a$, and produced $a$, where $p \leq v(a)$. There is an ex post efficient continuation equilibrium in which there is no renegotiation and $B$ accepts delivery of $a$ at the first opportunity, paying price $p$. This follows from Proposition 1, since if renegotiation were not possible, there would be an efficient continuation equilibrium equivalent to the above.

(b) Consider a history at which there has been no renegotiation, there is no outstanding offer, $\theta$ has been realized and no good has been produced. From Assumption 2, using arguments analogous to those in the proof of Lemma 3, there is an ex post efficient continuation equilibrium in which $S$ gets a share at most (approximately) $\lambda_{s}$ of the surplus. In this equilibrium:

(i) if there is no nomination, there is an ex post efficient continuation in which the parties negotiate as if there is no contract (and $S$ gets no more than $\lambda_{s}$ of the surplus).

(ii) If $S$ nominates $(p, a)$ such that $v(a)-p \leq \delta\left(1-\lambda_{s}\right) v(a)$, then $B$ does not exercise his option and in the renegotiation $B$ gets at least $\delta^{\gamma} \delta\left(1-\lambda_{s}\right) v(a)$ (valued at date 3$)$.

(iii) if $S$ nominates $(p, a)$ such that $v(a)-p>\delta\left(1-\lambda_{s}\right) v(a)$, then there is an arbitrary continuation equilibrium in which $B$ gets at least $\delta^{\gamma} \delta\left(1-\lambda_{s}\right) v(a)$ (since he can always exercise his option).

(c) Define a strategy profile $s^{2}$ as follows. At date $1, B$ invests $i_{b}^{*}$ and $S$ invests $i_{s}^{*}$. When $S$ is due to nominate a price, given that there has been no renegotiation so far:

(i) if $S$ has invested $i_{s} \geq i_{s}^{*}$ and $B$ has invested $i_{b}^{*}, S$ specifies price

$$
p=v\left(a\left(i_{s}, i_{b}^{*}, \theta\right)\right)-\frac{\delta^{-\gamma} \psi_{b}\left(i_{b}^{*}\right) \sigma\left(i_{s}, i_{b}^{*}, \theta\right)}{\delta^{2} E_{\theta} \sigma\left(i_{s}^{*}, i_{b}^{*}, \theta\right)}
$$

and the efficient good;

(ii) if the investments were $\left(i_{s}^{*}, i_{b}\right)$ for $i_{b} \neq i_{b}^{*}, S$ specifies price $p=v\left(a\left(i_{s}^{*}, i_{b}, \theta\right)\right)$ and the efficient good. 
After (i) or (ii), if there has been no renegotiation and there is no outstanding offer, $S$ produces the efficient good $a\left(i_{s}, i_{b}, \theta\right)$ and the continuation equilibrium is then as in (a) above.

If $S$ deviates from any of the above (including by underinvesting), the continuation equilibrium is as in (b) above, once $\theta$ has been realized.

At all other nodes continuation strategies are defined in a similar way to those in the proof of Proposition 2.

At the history described in (c)(i) above, $S$ 's continuation payoff under $s^{2}$ is (valued at a production date)

$$
\left.\sigma\left(i_{s}, i_{b}^{*}, \theta\right)\right)-\frac{\psi_{b}\left(i_{b}^{*}\right) \sigma\left(i_{s}, i_{b}^{*}, \theta\right)}{\delta^{2} E_{\theta} \sigma\left(i_{s}^{*}, i_{b}^{*}, \theta\right)}
$$

while, if she deviates, she gets at most $\lambda_{s} \sigma\left(i_{s}, i_{b}^{*}, \theta\right)$ which is lower by (5) (for $i_{s}=i_{s}^{*}$ ).

At the history in (c)(ii), her continuation payoff is equal to the available surplus if she conforms to $s^{2}$, so deviation is not optimal.

If $S$ invests $i_{s}^{*}, B$ 's expected continuation payoff is $\psi_{b}\left(i_{b}^{*}\right)$, so $S$ gets the full surplus. If she invests $i_{s}<i_{s}^{*}$, her payoff is at most

$$
\lambda_{s} \delta^{2} E_{\theta} \sigma\left(i_{s}, i_{b}^{*}, \theta\right)-\psi_{s}\left(i_{s}\right)
$$

so this deviation is suboptimal by (5).

If she invests $i_{s} \geq i_{s}^{*}$, her payoff is

$$
E_{\theta} \delta^{2} \sigma\left(i_{s}, i_{b}^{*}, \theta\right)-\psi_{s}\left(i_{s}\right)-\frac{\psi_{b}\left(i_{b}^{*}\right) E_{\theta} \sigma\left(i_{s}, i_{b}^{*}, \theta\right)}{E_{\theta} \sigma\left(i_{s}^{*}, i_{b}^{*}, \theta\right)}
$$

which is maximized by $i_{s}^{*}$. $B$ 's payoff at the outset of the game is

$$
-\psi_{b}\left(i_{b}^{*}\right)+\delta^{2+\gamma} E_{\theta} \frac{\delta^{-\gamma} \psi_{b}\left(i_{b}^{*}\right) \sigma\left(i_{s}^{*}, i_{b}^{*}, \theta\right)}{\delta^{2} E_{\theta} \sigma\left(i_{s}^{*}, i_{b}^{*}, \theta\right)}=0
$$

if he invests $i_{b}^{*}$ and his continuation payoff is zero if he invests any other amount. Therefore it is optimal for him to invest $i_{b}^{*}$. As in the proof of Proposition 2, the parties cannot both benefit from renegotiation from $\alpha^{s}$ because the continuation is always efficient. This establishes that $s^{2}$ is an equilibrium. Q.E.D. 


\section{REFERENCES}

Aghion, P., and P. Bolton (1992), "An Incomplete Contracts Approach to Financial Contracting", Review of Economic Studies, 59, 473-493.

Aghion, P., M. Dewatripont and P. Rey (1994), "Renegotiation Design with Unverifiable Information", Econometrica 62, 257-282.

Aghion, P., M. Dewatripont and P. Rey (2002), "On Partial Contracting", European Rconomic Review, 46, 745-753.

Bewley, T. (1997), "A Depressed Labor Market, as Explained by Participants", mimeo, Yale.

Bolton, P., and M. Dewatripont (2005). Contract Theory. MIT Press.

Bolton, P. and A. Rajan (2001), "The Employment Relation and the Theory of the Firm: Arm's Length Contracting versus Authority", mimeo, Princeton.

Borges, B. and J. Knetsch (1997), "Valuation of Gains and Losses: Fairness and Negotiation Outcomes", International Journal of Social Economics, 24, 265-81.

Carmichael, L. and W.B. MacLeod (2003), "Caring About Sunk Costs: A Behavioral Solution to Hold-up Problems with Small Stakes", Journal of Law, Economics and Organization, 19, 106-119.

Che, Y-K., and D. Hausch (1999), "Cooperative Investments and the Value of Contracting", American Economic Review 89, 125-147.

Che, Y-K., and J. Sakovics (2003), "A Dynamic Theory of Holdup", mimeo.

Chung, T. (1991), "Incomplete Contracts, Specific Investments and Risk-Sharing", Rev. Econ. Stud, 58, 1031-1042.

Demski, J. and D. Sappington (1991), "Resolving Double Moral Hazard Problems with Buyout Agreements", Rand Journal of Economics 22(2), 232-40.

Edlin, A. and B. Hermalin (2000), "Contract Renegotiation and Options in Agency Problems", Journal of Law, Economics and Organization 16, 395-423.

Edlin, A. and S. Reichelstein (1996), "Holdups, Standard Breach Remedies, and Optimal Investment", American Economic Review 86, 478-501.

Grossman, S. and O. Hart (1986), "The Costs and Benefits of Ownership: A 
Theory of Lateral and Vertical Integration", Journal of Political Economy, 94, 691719.

Hart, O. and J. Moore (1988), "Incomplete Contracts and Renegotiation", Econometrica 56, 755-785.

Hart, O. and J. Moore (1999), "Foundations of Incomplete Contracts", Rev. Econ. Stud, 66, 115-138.

Hermalin, B. and M. Katz (1991), "Moral Hazard and Verifiability: the Effects of Renegotiation in Agency", Econometrica 59(6), 1735-53.

Kahneman, D., J. Knetsch and R. Thaler (1986), "Fairness as a Constraint on Profit Seeking: Entitlements in the Market", American Economic Review, 76, 72841.

Klein, B. Crawford, R. and A. Alchian (1978), "Vertical Integration, Appropriable Rents, and the Competitive Contracting Process", Journal of Law and Economics, 21, 297-326.

Levin, J. (2003), "Relational Incentive Contracts", American Economic Review, 93, 835-57.

MacLeod, W. B. and J. M. Malcomson (1989), "Implicit Contracts, Incentive Compatibility, and Involuntary Unemployment", Econometrica, 57, 447-80.

Maskin, E. and J. Moore (1999), "Implementation and Renegotiation", Review of Economic Studies, 66, 39-56.

Maskin, E. and J. Tirole (1999a), "Unforeseen Contingencies and Incomplete Contracts", Rev. Econ. Stud, 66, 83-113.

Nöldeke, G. and K. Schmidt (1995), "Option Contracts and Renegotiation: a Solution to the Holdup Problem", Rand J. Econ 26, 163-179.

Nöldeke, G. and K. Schmidt (1998), "Sequential Investments and Options to Own", Rand J. Econ

Segal, I. (1999), "Complexity and Renegotiation: A Foundation for Incomplete Contracts", Rev. Econ. Stud. 66, 57-82.

Shaked, A. (1994), "Opting Out: Bazaars versus 'High Tech' Markets", Investigaciones Economicas, XVIII, 421-432. 
Watson, J. (2001), "Contracts, Mechanism Design and Technological Detail", mimeo, UCSD.

Williamson, O. (1979), "Transactions-Cost Economics: The Governance of Contractual Relations", Journal of Law and Economics, 22, 233-262.

Williamson, O. (1983), "Credible Commitments: Using Hostages to Support Exchange", American Economic Review, 73, 519-540. 